BLS 33, No 2 2007. DOI: http://dx.doi.org/10.3765/bls.v33i2.3502

(published by the Berkeley Linguistics Society and the Linguistic Society of America)

\title{
Phonemic Versus Phonetic Correlates of Vowel Length in Chuxnabán Mixe
}

\author{
CARMEN JANY \\ University of California, Santa Barbara
}

\section{Introduction}

This paper tests for a possible three-way phonemic vowel length distinction in Chuxnabán Mixe and examines the phonetic correlates of vowel length, in addition to describing this previously undocumented variety of Mixe.

Chuxnabán Mixe is a Mixe-Zoque language spoken by about nine hundred people in one village in Oaxaca. The Mixe territory is located in the north-eastern part of the Mexican state of Oaxaca. It is composed of two hundred and ninety communities divided into nineteen municipalities (Torres Cisneros 1997). Each community speaks a different variety of Mixe, some of which are mutually unintelligible. In many cases it has yet to be determined whether a particular variety represents a distinct language or dialect, as the documentation of Mixe languages is limited. The Ethnologue lists ten different languages divided into three larger branches: Eastern Mixe with six languages and Veracruz Mixe and Western Mixe with two languages each (Gordon 2005). Chuxnabán Mixe has been identified by its speakers as Midland Mixe, and is assumed to correspond to Quetzaltepec Mixe in the Ethnologue entry. At present, there are only a few published grammars and dictionaries of the Mixe languages (De la Grasserie 1898; Hoogshagen 1997; Ruiz de Bravo Ahuja 1980; Schoenhals 1982; Van Haitsma 1976).

The Mixe languages vary greatly in their vowel systems (Suslak 2003). For instance, while Totontepec Mixe has nine phonemic vowels (Schoenhals 1982), only six are reported for Coatlán Mixe (Hoogshagen 1959, 1997). All Mixe languages show a phonemic vowel length distinction and a phonemic phonation contrast between plain, aspirated, and glottalized vowels. The scarce documentation of these languages has led to a very limited number of studies concerned with these unique and typologically interesting vowel systems.

While a distinction between short and long vowels is very common among the world's languages, a three-way phonemic vowel length contrast is typologically rare (Ladefoged and Maddieson 1996). Such a contrast has been reported for Coatlán Mixe and San José El Paraíso Mixe (Hoogshagen 1959; Van Haitsma 


\section{Carmen Jany}

1976). The closely related Chuxnabán Mixe potentially represents an additional example for this uncommon phenomenon. While Hoogshagen (1959) reports for Coatlán Mixe that the three-way length contrast does not depend on syllable structure, vowel quality, preceding or following consonants, or intonation, no systematic phonetic measurements have been taken. In order to explore a possible three-way contrast in Chuxnabán Mixe, vowel duration is measured for a set of elicited nouns, and potential phonetic correlates are examined. In the first part of this paper phonological contrasts in Chuxnabán Mixe are treated. The second part describes the methodology and results of the vowel length study.

\section{Phoneme Inventory and Phonation Contrasts}

Chuxnabán Mixe has at least seven phonemic vowel qualities. It remains unclear whether schwa is a phoneme or merely an allophone of either the mid front vowel /e/ or the central high vowel /i/. Schwa appears in some verbal suffixes and word-finally, but no minimal pair has been identified so far. Another vowel of unclear status is the central rounded $[\Theta]$. It occurs in the data from two speakers in yö'öpy 'to walk' and in two other verbs. Comments from other speakers suggest that this may be the result of dialect borrowing. The vowel phonemes are summarized in (1). Corresponding symbols in the newly established orthography, ${ }^{1}$ if different, are included to the right in brackets. Phonemic contrasts are illustrated in (2).

(1) Vowel Phonemes

\begin{tabular}{|c|c|c|}
\hline $\mathrm{i}$ & $\mathrm{i}(\mathrm{i})$ & $\mathrm{u}$ \\
\hline $\mathrm{e}$ & & $\mathrm{o}$ \\
\hline$æ(\ddot{a})$ & $\mathrm{a}$ & \\
\hline
\end{tabular}

(2) Minimal Pairs

$\begin{array}{lllllll}\mathrm{i} \sim \ddot{\mathrm{i}} & \text { tsip } & \text { 'war' } & \text { tsïp } & \text { 'plant name' } & \\ \mathrm{a} \sim \mathrm{u} & \text { kam } & \text { 'field' } & \text { kum } & \text { 'sweet fruit' } & & \\ \ddot{\mathrm{a}} \sim \mathrm{u} & \text { tsäk } & \text { 'dull' } & \text { tsuk } & \text { 'mouse' } & & \\ \mathrm{o} \sim \mathrm{u} \sim \ddot{\mathrm{i}} & \text { joon } & \text { 'bird' } & \text { juun } & \text { 'hard' } & \text { jïin } & \text { 'fire' }\end{array}$

In addition to distinguishing short and long vowels, the complex vowel system shows a phonemic contrast between modal, breathy or aspirated, and glottalized or creaky vowels. A possible three-way vowel length distinction is examined in this study. Overall, the following types of syllable nuclei are found: V, VV, Vh, VVh, $\mathrm{V}^{\text {? }}$, and $\mathrm{V}^{2} \mathrm{~V} .^{2}$ These contrasts are illustrated in (3).

\footnotetext{
${ }^{1}$ A practical orthography has been established in collaboration with the speakers, based on local literacy efforts (INEA 1994 and 1997), descriptions of other Mixe varieties, and Spanish.

${ }^{2}$ Evidence for a phonemic distinction between Vh and VVh still needs to be found.
} 
(3) Minimal Pairs and Near Minimal Pairs

\begin{tabular}{|c|c|c|c|c|}
\hline $\mathrm{O} \sim \mathrm{oO}$ & $\operatorname{mox}$ & 'stomach' & $\operatorname{moox}$ & 'knot' \\
\hline $\mathrm{a} \sim \mathrm{aa}$ & kam & 'field' & kaan & 'salt' \\
\hline $\mathrm{e} \sim \mathrm{ee}$ & kepy & 'tree' & keepy & 'bream' \\
\hline $\mathrm{a} / \mathrm{aa} \sim \mathrm{aah}$ & taak & 'mother' & taajk & 'police' \\
\hline & pak & ‘pigeon’ & paajk & 'bone' \\
\hline$\dddot{\mathrm{i}} / \mathrm{iii} \sim \dddot{\mathrm{iïh}}$ & miït & 'they went' & miïjk & 'year’ \\
\hline & mik & 'strong' & xï̈k & 'bean' \\
\hline$a \sim a^{?}$ & täp & 'you have' & $k \ddot{a} p$ & 'scorpion' \\
\hline $\mathrm{u} \sim \mathrm{u}^{?}$ & tsuk & 'mouse' & ju’k & 'owl' \\
\hline$\ddot{i} \sim \ddot{1} ?$ & mik & 'strong' & mï't & 'mother-in-law, father-in-law' \\
\hline $\mathrm{ii} \sim \mathrm{i}$ i & kiix & 'woman' & pi’ix & 'tail' \\
\hline $\mathrm{uu} \sim \mathrm{u}^{\mathrm{P}} \mathrm{u}$ & puuy & 'seat' & pu'uy & 'table' \\
\hline$\ddot{i} \sim \ddot{1} \dddot{i}$ & tsïp & 'plant name' & tsï̈̈p & 'plant when getting cut' \\
\hline $\mathrm{u}^{\mathrm{P}} \sim \mathrm{u}^{\mathrm{P}} \mathrm{u}$ & pu'ts & 'yellow' & pu'uts & 'infection' \\
\hline aaj $\sim a^{2} a$ & paajk & 'bone' & $p a^{\prime} a k$ & 'sweet' \\
\hline
\end{tabular}

While non-modal phonation in the form of breathiness occurs only in the last portion of the vowel, glottalization or creakiness can be found in the last, the middle, or the first portion of a vowel. These timing differences are related to differences in function. The first two involve a phonemic contrast between plain, glottalized, and interrupted vowels. The third occurs in vowel-initial words where a glottal stop is inserted at the beginning to function as onset. Syllable onsets are obligatory in Chuxnabán Mixe, the same as in other Mixe languages (Crawford 1963, Schoenhals 1982, Van Haitsma 1976). A detailed phonetic description of the phonation contrasts can be found in Jany (2004).

The consonant system of Chuxnabán Mixe is fairly simple. There are fifteen consonantal phonemes, although the rhotic and lateral occur only in loans. The consonants are summarized in (4). Corresponding symbols in the newly established orthography, ${ }^{3}$ if different, are included to the right in brackets.

Except for the rhotic, the lateral, and the two glides, all consonants can be palatalized. ${ }^{4}$ Palatalization in Chuxnabán Mixe, as in other Mixe languages (Hoogshagen 1997; Schoenhals 1982; Van Haitsma 1976), is a suprasegmental phoneme affecting not only the palatalized consonant, but adjacent vowels as

\footnotetext{
3 A practical orthography has been established in collaboration with the speaker, based on local literacy efforts (INEA 1994 and 1997), descriptions of other Mixe varieties, and Spanish.

${ }^{4}$ Palatalization is represented in the orthography by a palatal glide / $y /$ following the palatalized consonant.
} 


\section{Carmen Jany}

well. This is manifested by an onglide and an offglide, if the palatalized consonant occurs word-medially. The glottal stop has only been identified as a phoneme when it forms part of a syllable nucleus, hence in $\mathrm{V}^{2}$ and $\mathrm{V}^{2} \mathrm{~V}$. The glottal fricative $/ \mathrm{h} /$ functions as a phoneme in onset and coda position, as well as being a part of the nucleus, with different phonetic realizations in each prosodic position.

(4) Consonants

\begin{tabular}{|l|c|c|c|c|c|c|}
\hline & Bilabial & Alveolar & Postalveolar & Palatal & Velar & Glottal \\
\hline Plosives & $\mathrm{p}$ & $\mathrm{t}$ & & & $\mathrm{k}$ & ? $\left({ }^{(}\right)$ \\
\hline Nasals & $\mathrm{m}$ & $\mathrm{n}$ & & & & \\
\hline Fricatives & & $\mathrm{s}$ & $\int(\mathrm{x})$ & & & $\mathrm{h}(\mathrm{j})$ \\
\hline Affricates & & $\mathrm{ts}$ & $\mathrm{t} \int(\mathrm{ch})$ & & & \\
\hline Rhotic & & $\mathrm{r}$ & & & & \\
\hline Lateral & & $\mathrm{l}$ & & & & \\
\hline Glides & $\mathrm{w}$ & & & $\mathrm{y}$ & & \\
\hline
\end{tabular}

Allophonic variations similar to those found in other Mesoamerican languages (Campbell et al. 1986) have also been observed. Obstruents, i.e. plosives, fricatives, and affricates, are voiced following a nasal in word-medial position and in intervocalic position, but are always voiceless in word-final position. Nasals are devoiced after voiceless obstruents word-finally.

\section{Vowel Length Study}

\subsection{Background}

Coatlán Mixe and San José El Paraíso Mixe have been described as having a three-way phonemic vowel length distinction (Hoogshagen 1959; Van Haitsma 1976), which is typologically rare. Such a phonemic distinction also occurs in Yavapai (Tomas and Shaterian 1990) and Estonian (Lehiste 1970). Hoogshagen (1959) reports that the three-way length contrast in Coatlán Mixe does not depend on syllable structure, vowel quality, surrounding consonants, or intonation. Thomas and Shaterian (1990) conclude that in Yavapai vowel length is not predictable from other phenomena present in the language, such as pitch factors or syntactic category. In Estonian, however, the third degree of vowel length is dependent on syllable structure and word patterning (Lehiste 1970).

In general, vowel duration can be influenced by many factors, such as vowel position and the number of syllables in a word, vowel quality, and the following consonant, among others. Hoogshagen (1959) examined such possible effects on vowel length for Coatlán Mixe but found no influencing factors. Nevertheless, according to Hoogshagen (1997) the three-way contrast is hard to hear for speakers, and is, therefore, not represented in the orthography. A phonemic distinction between short and long vowels has been attested for all Mixe varieties, and is included in their orthographies. 
This study examines Hoogshagen's findings for a different variety of Mixe. While Hoogsagen's conclusions are not based on systematic phonetic measurements, the present study tests for a possible three-way phonemic length distinction in Chuxnabán Mixe by taking detailed measurements and considering all possible influencing factors, such as syllable structure and phonetic environment. In addition, potential phonetic correlates of vowel length are examined.

\subsection{Methodology}

For the purpose of this study first the minimal triplets cited in Hoogshagen (1959) for Coatlán Mixe were elicited in Chuxnabán Mixe, and the vowel lengths were measured. Second, a list of monosyllabic nouns containing all possible syllable nuclei and codas and combinations thereof was assembled, a total of a hundred and ninety-five words. Each target word was recorded three times in a carrier phrase from two female speakers. Vowel duration (including creakiness and breathiness) was then measured for each token.

Vowel duration cross-linguistically is often influenced by the vowel position and the number of syllables in a word, the vowel quality, and the following consonant. For example, low vowels tend to be longer than high vowels, and voiced codas may trigger vowel lengthening. To avoid such confounding factors, syllable structure and coda types were kept constant in the comparisons: 1) only monosyllabic words were recorded, 2) length ratios were examined rather than duration across vowel qualities, and 3) codas were considered for voicing and palatalization. While low vowels may be longer than other vowels, length ratios for all vowel qualities were expected to remain equal. Since voiced codas may trigger vowel lengthening and palatalization affects surrounding vowels in Mixe, only data sets with codas in the same group were compared. Furthermore, differences in phonation were considered. Phonation contrasts have been associated with various phonetic properties, such as differences in periodicity, intensity, spectral tilt, fundamental frequency, formant frequencies, duration, and airflow (Gordon and Ladefoged 2001). In this study durational effects of non-modal phonation were examined across all vowel qualities and compared. Non-modal vowels generally correlate with increased duration when compared to their modal counterparts (Gordon 1998). This was tested for Chuxnabán Mixe.

\subsection{Results}

Only two of the triplets reported for Coatlán Mixe (Hoogshagen 1959) have yielded comparable results in Chuxnabán Mixe. They are summarized in (5). It is apparent that the Chuxnabán Mixe triplets do not show a three-way length distinction. While there is a clear difference between short and long vowels, in accord with short and extra-long vowels in Coatlán, the words with long vowels in Coatlán poox 'spider' and peet 'broom' correspond to words with complex codas in Chuxnabán, poxm and pätn respectively, having the shortest vowels of the three, i.e. with a duration of 0.202 and 0.132 seconds accordingly. Overall, the 


\section{Carmen Jany}

elicitation of possible triplets has not provided any proof for a three-way length contrast in Chuxnabán Mixe.

(5) Minimal triplets from Coatlán Mixe in Chuxnabán Mixe

\begin{tabular}{|l|l|l|l|l|l|l|}
\hline & $\mathrm{V}$ & & VV & & VVV & \\
\hline Coatlán & pox & 'guava' & poox & 'spider' & pooox & 'knot' \\
\hline Chuxnabán & $\begin{array}{l}\text { pox } \\
.239 \mathrm{~s}\end{array}$ & 'guava' & $\begin{array}{l}\text { poxm } \\
.202 \mathrm{~s}\end{array}$ & 'spider' & $\begin{array}{l}\text { moox } \\
.365 \mathrm{~s}\end{array}$ & 'knot' \\
\hline Coatlán & $p e t$ & 'climb' & peet & 'broom' & peeet & 'Peter' \\
\hline Chuxnabán & $\begin{array}{l}\text { pät } \\
.139 \mathrm{~s}\end{array}$ & 'climb' & $\begin{array}{l}\text { pätn } \\
.132 \mathrm{~s}\end{array}$ & 'broom' & $\begin{array}{l}\text { päät } \\
.281 \mathrm{~s}\end{array}$ & 'Peter' \\
\hline
\end{tabular}

Even though no triplets with a phonemic three-way length contrast were identified, the duration measurements of the elicited wordlist gave some insights into vowel length. Contrary to expectations coda voicing and palatalization did not have a major effect on vowel length. Rather, having a postalveolar fricative $/ \mathrm{x} /$ as coda resulted in clearly longer vowels. This is illustrated in (6) and (7) for the short modal vowel /a/. In (6) and (7) the voiced codas, i.e. the nasals, do not correlate with greater duration of the vowel. Palatalized codas, such as /chy/ and /xy/ in (6), do not consistently correlate with greater vowel duration when compared to corresponding non-palatalized codas. Similar results were found for other vowel qualities and types of syllable nuclei.

Words lacking an onset had significantly longer vowels. This is shown in (8) where the $\mathrm{V}$ in CVk is clearly shorter than the $\mathrm{V}$ in Vk. The same pattern occurs with CVky and Vky in (8). It has to be noted that onsetless syllables are not permitted in Mixe. In these situations an initial glottal stop is inserted. Phonetically, this glottal stop is realized as creakiness during the first portion of the vowel. This lengthening effect in 'onsetless' syllables can be explained by the fact that non-modal phonation generally correlates with greater vowel duration.

(6) Speaker 1: Vowel length for short modal /a/ by coda

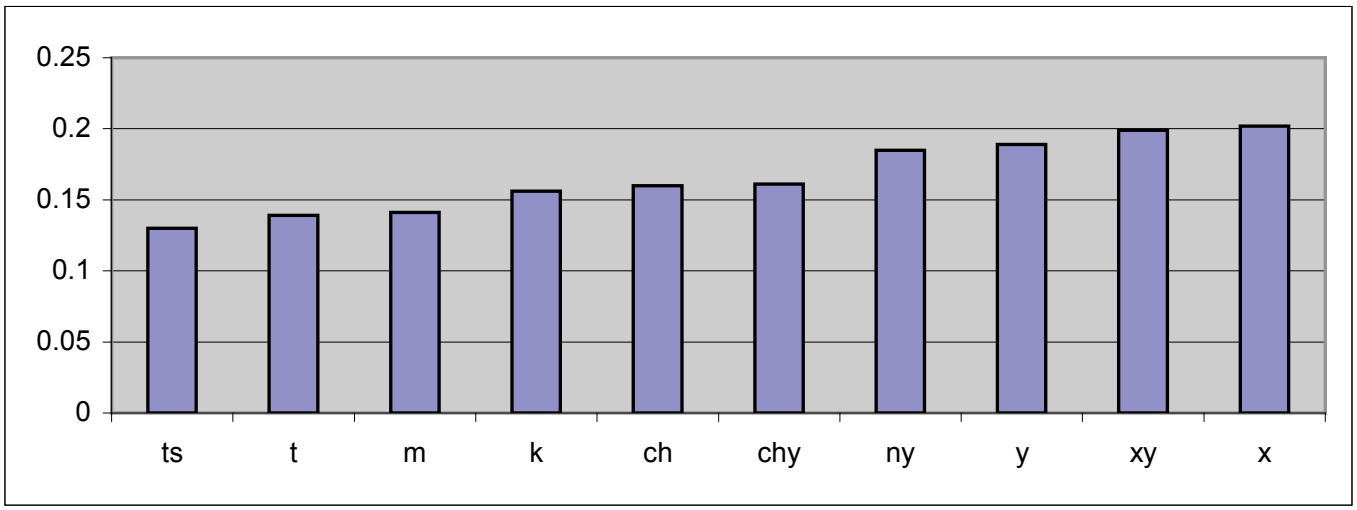




\section{Vowel Length in Chuxnabán Mixe}

(7) Speaker 2: Vowel length for short modal /a/ by coda

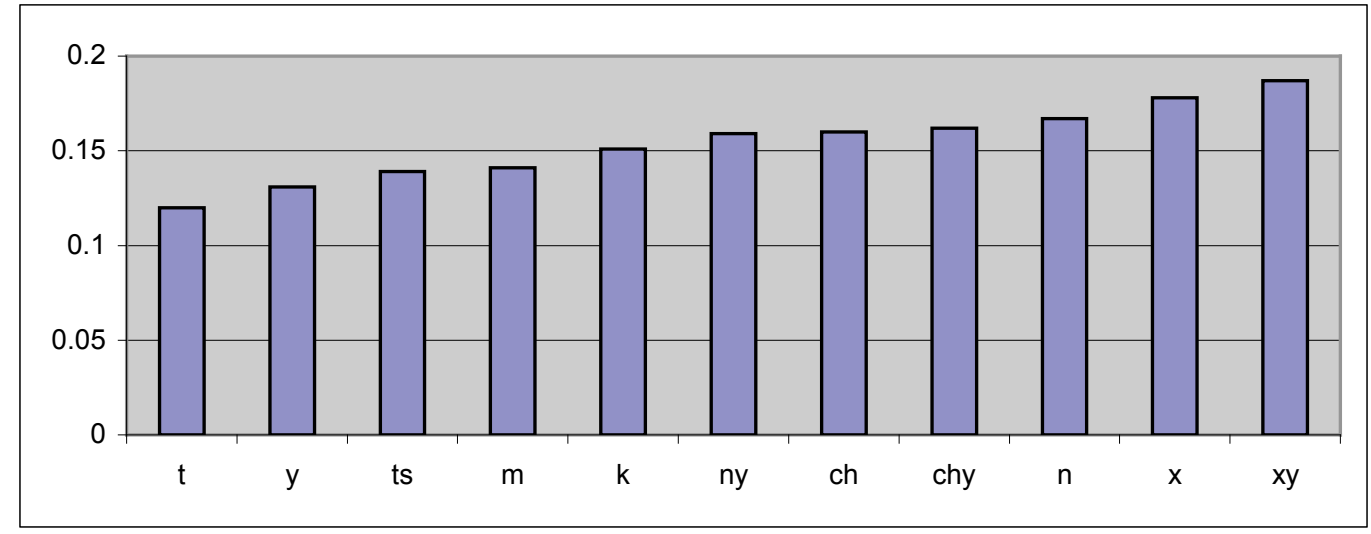

(8) Speaker 2: Vowel length for short modal /u/ by coda and prosodic structure

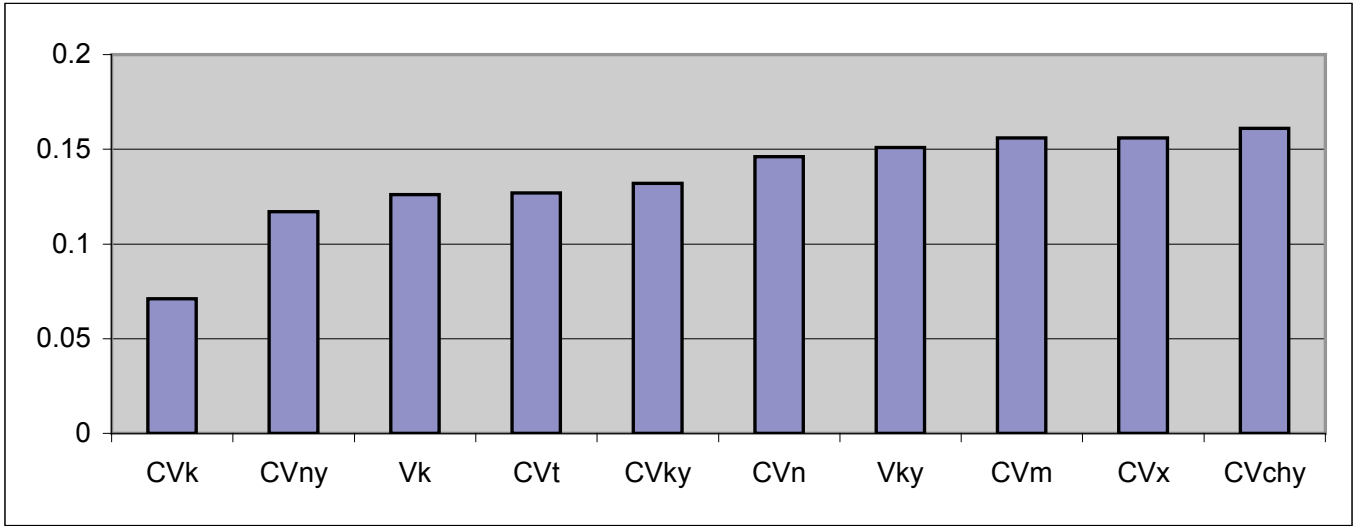

(9) Speaker 1: Vowel length for long modal/aa/ by coda and prosodic structure

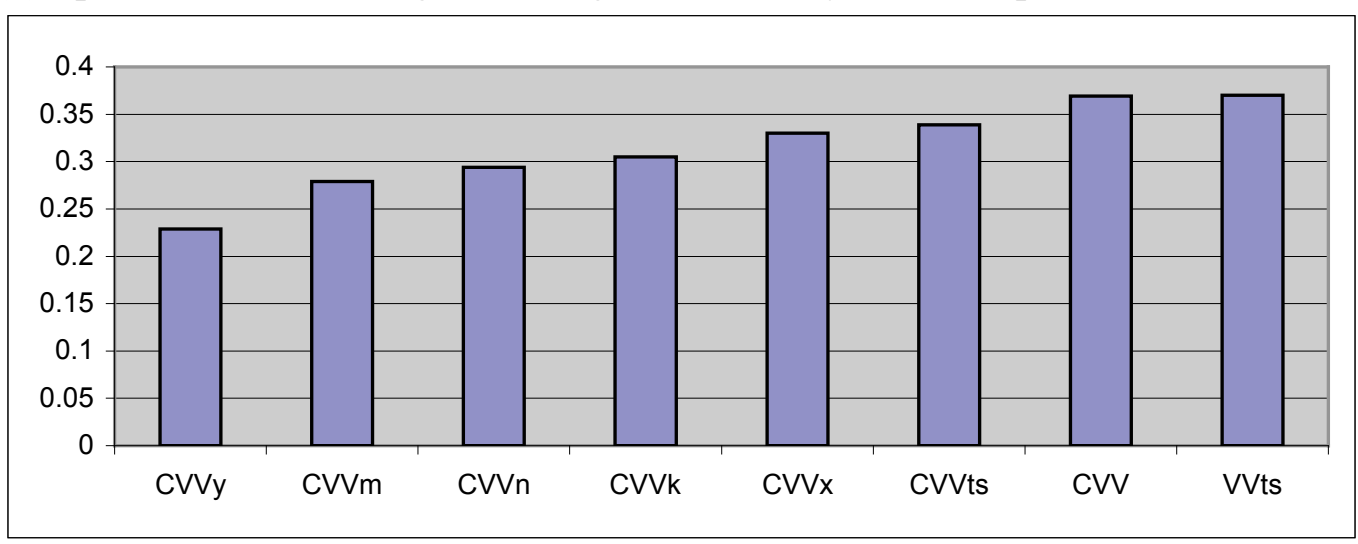

Onsetless vowels are also longer in other types of syllable nuclei. This is shown for the long modal vowel /aa/ in (9). In addition, vowels in open syllables tend to be longer than vowels in closed syllables, as illustrated in (9) where CVV and 


\section{Carmen Jany}

VVts show the greatest durations. Long vowels show greater variation in length according to coda type and syllable type than short vowels. This can be seen when comparing (6), (7), and (9), i.e. results for short and long /a/. It is unlikely that this variation stems from a phonological three-way contrast in length, as results for other long vowels show more consistency.

In addition to the influencing factors presented so far: coda $/ \mathrm{x} /$ and syllables lacking onsets or codas, vowel length in words with glides as onsets or codas also shows variation, given that it is difficult to determine the exact boundaries for the measurements. Excluding these confounding factors length ratios for short versus long vowels remain constant across vowel qualities. This is shown in (10).

(10) Vowel length for short versus long vowels

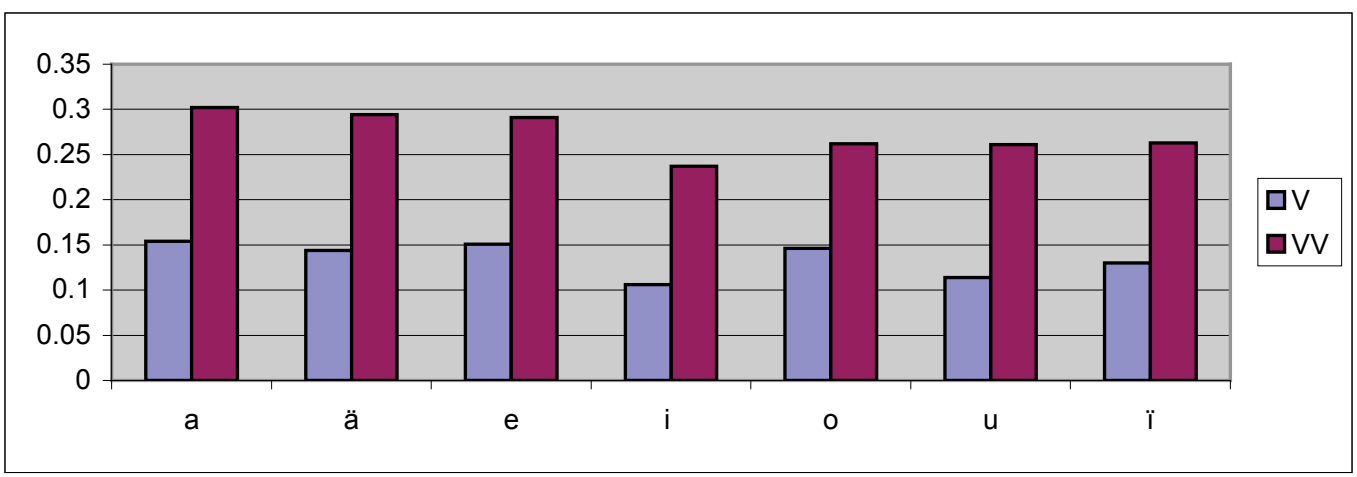

The duration effects of non-modal phonation have also been examined in this study. In general, it is expected that glottalized and breathy vowels are longer than their modal counterparts. However, the results indicate that non-modal phonation does not always correlate with increased duration as in other languages (Gordon and Ladefoged 2001). Glottalized vowels, i.e. vowels in $\mathrm{V}^{2}$ syllable types, are longer than their short modal counterparts, but interrupted vowels, i.e. vowels in $\mathrm{V}^{2} \mathrm{~V}$ syllable types, are shorter than their long modal counterparts. This is shown in (11) and (12).

(11) Vowel length for short modal versus short glottalized vowels: $\mathrm{V}<\mathrm{V}^{\text {? }}$

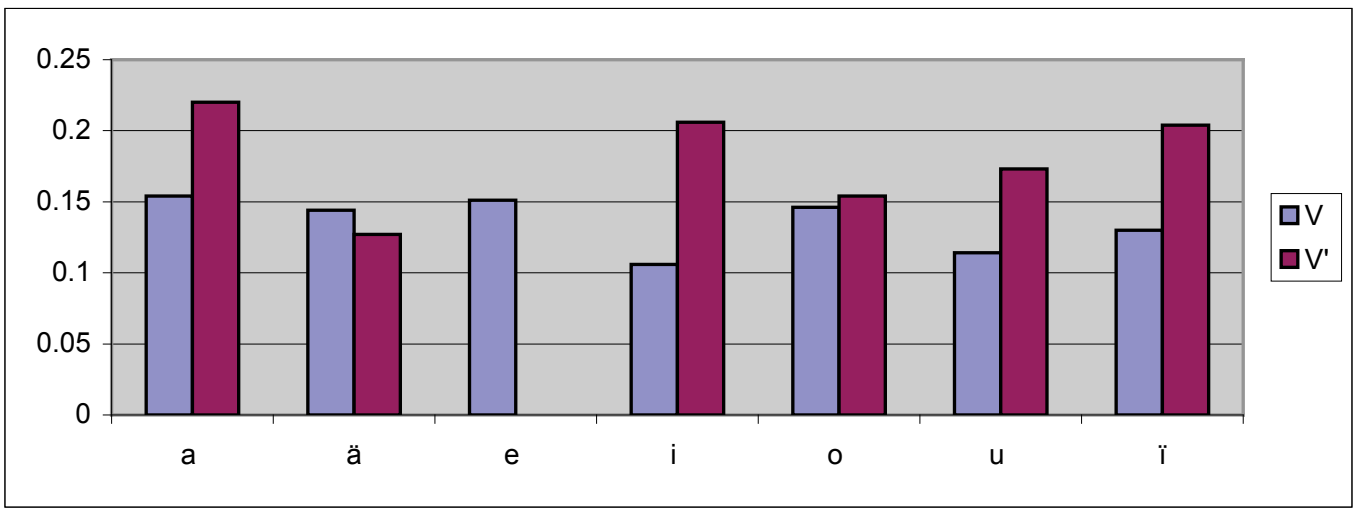


(12) Vowel length for long modal versus interrupted vowels: VV $>V^{\prime} V$

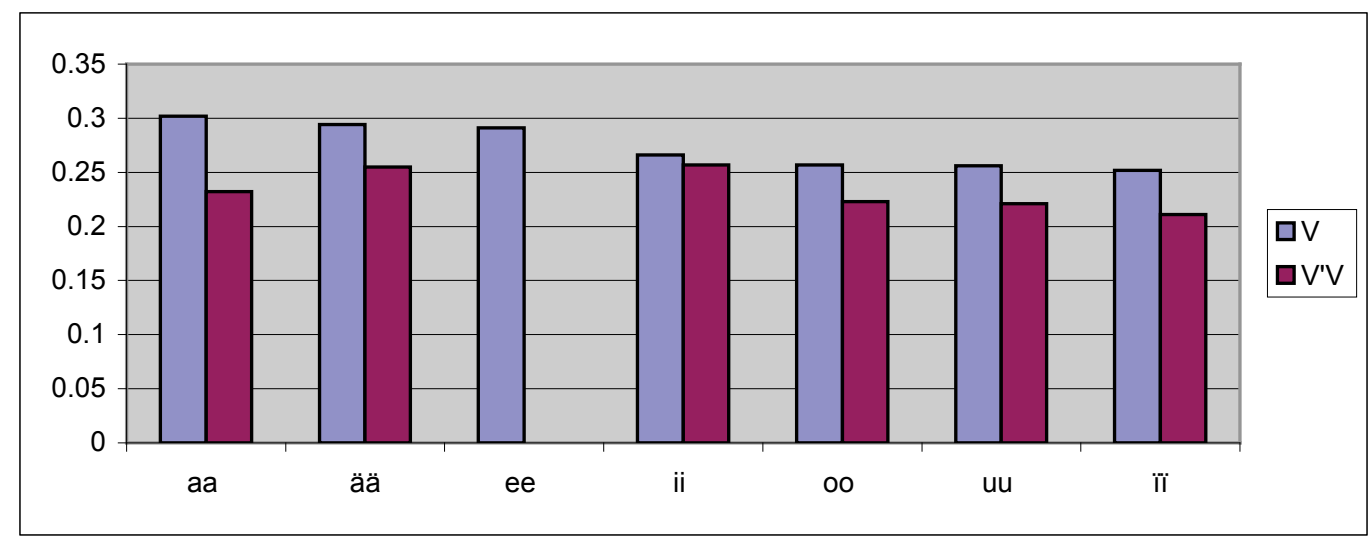

(13) Vowel length for modal versus aspirated vowels: $\mathrm{VVh}>\mathrm{VV}>\mathrm{Vh}>\mathrm{V}$

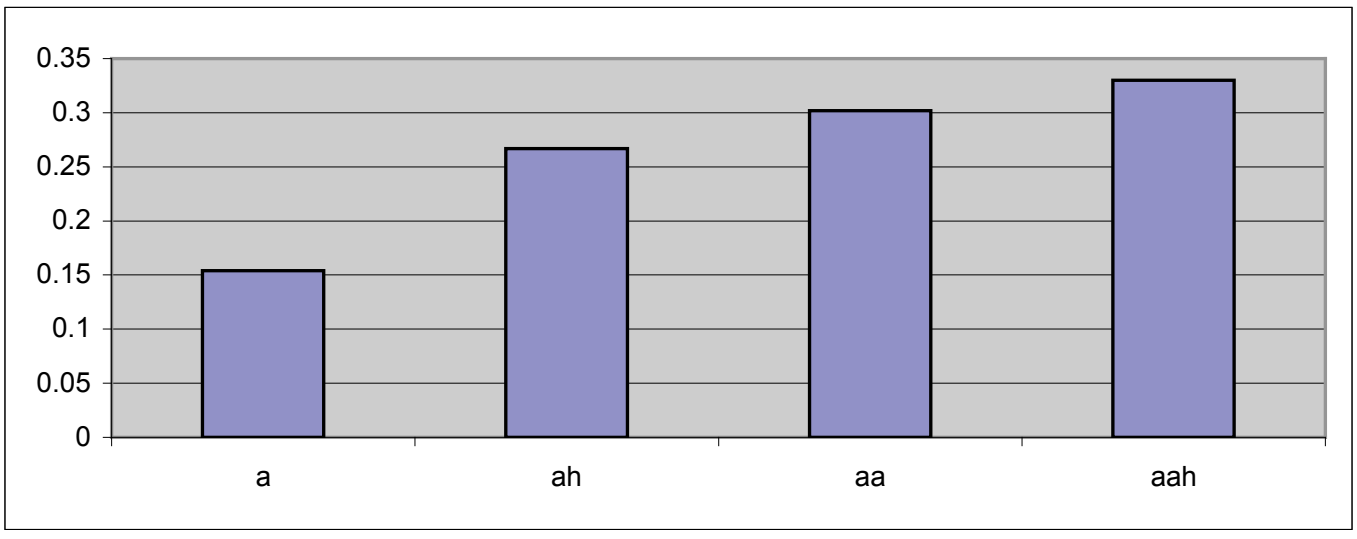

The results for the aspirated vowels show that breathy vowels are longer than their modal counterparts, hence confirming Gordon and Ladefoged's (2001) observations. The length difference between $\mathrm{V}$ and $\mathrm{Vh}$ is significantly greater than between VV and VVh. This is illustrated in (13) for the vowel /a/. While there is a clear distinction between short and long aspirated vowels, no minimal pairs have been identified so far.

To sum up, a three-way phonemic length contrast has not been found for Chuxnabán Mixe. Vowel lengthening is triggered by either the insertion of a glottal stop in 'onsetless' syllables, lack of coda, or by having a coda $/ \mathrm{x} /$, rather than by palatalization or voiced codas. The modal long vowels show some variation even after determined influencing factors have been excluded. The duration results for modal versus non-modal phonation can be summarized as follows: (1) Short modal vowels are always shorter than long modal vowels and any corresponding non-modal vowels, i.e. short glottalized, interrupted, and aspirated counterparts. (2) In general, modal vowels are shorter than their non-modal counterparts, except for the interrupted vowels. (3) Interrupted vowels are longer than short modal vowels, but shorter than long modal vowels. 


\section{Carmen Jany}

\section{Conclusions}

I have shown that vowel length, i.e. short versus long vowels, and phonation contrasts are phonemic in Chuxnabán Mixe, the same as in other Mixe varieties. As a result, the following syllable nuclei have been identified: V, VV, Vh, VVh, $V^{2}$, and $V^{2} V$. No evidence has been found for a three-way phonemic vowel length contrast. However, the duration measurements have revealed certain influencing factors, such as syllable structure and coda type, that can trigger vowel lengthening. Furthermore, the study of potential effects of non-modal phonation on vowel length has shown that in general non-modal vowels are longer than their modal counterparts with one exception: interrupted vowels are shorter than corresponding long modal vowels.

By describing and examining Chuxnabán Mixe vowels, this work intends to lay the ground for future phonetic analyses of the complex and typologically interesting vowel systems found in this and other Mixe languages. Further investigations may include: (1) Measurements in polysyllabic words to examine the effects of position in word, stress, and intonation on vowel length, (2) Data collection from more speakers to include statistic evaluation of results, (3) Length measurements for Coatlán Mixe triplets to confirm Hoogshagen's (1959) results, and (4) Collection an analysis of data from other Mixe varieties.

\section{References}

Campbell, Lyle, Terrence Kaufman, Thomas C. Smith-Stark. 1986. MesoAmerica as Linguistic Area. Language 62(3):530-570.

Crawford, John Chapman. 1963. Totontepec Mixe Phonotagmemics. Summer Institute of Linguistics 8. University of Oklahoma.

De La Grasserie, Raoul. 1898 (reprint 1968). Langue Zoque et Langue Mixe: Grammaire, Dictionnaire. Biliothèque Linguistique Américaine, Tome XXII. Paris. (Reprint: Kraus. Nendeln, Liechtenstein).

Gordon, Matthew. 1998. The phonetics and phonology of non-modal vowels: A cross-linguistic perspective. Berkeley Linguistics Society 24:93-105

Gordon, Matthew and Peter Lagefoged. 2001. Phonation types: a cross-linguistic overview. Journal of Phonetics 29:383-406.

Gordon, Raymond G., Jr. (ed.). 2005. Ethnologue: Languages of the World. $15^{\text {th }}$ Edition. Dallas, Texas: SIL International. http://www.ethnologue.com/

Hoogshagen, Searle. 1959. Three contrastive vowel lengths in Mixe. Zeitschrift für Phonetik und allgemeine Sprachwissenschaft 12:111-15.

Hoogshagen Noordsy, Searle and Hilda Halloran Hoogshagen. 1997. Diccionario Mixe de Coatlán Oaxaca. Summer Institute of Linguistics. Mexico.

INEA (Instituto Nacional para la Educación del los Adultos). 1994. Ayuk Ja'jy Y'ayuujk. Libro del Adulto, Población Mixe (Parte Baja), Oaxaca. Source: http://cdi.gob.mx/index.php?id seccion=519.

INEA (Instituto Nacional para la Educación del los Adultos). 1997. Ayuk Ja’jy 
Y'ayuujk. Libro del Adulto, Población Mixe (Parte Alta), Oaxaca. Source: http://cdi.gob.mx/index.php?id seccion=519 .

Jany, Carmen. 2006. Vowel Length and Phonation Contrasts in Chuxnabán Mixe. Santa Barbara Papers in Linguistics 18: Proceedings from the $9^{\text {th }}$ Annual Workshop on Native American Languages. University of California, Santa Barbara.

Ladefoged, Peter And Ian Maddieson. 1996. The Sounds of the World's Languages. Blackwell, Malden, MA.

Lehiste, Ilse. 1970. Suprasegmentals. MIT Press, Cambridge, MA.

Lyon, Shirley. 1967. Tlahuitoltepec Mixe Clause Structure. International Journal of American Linguistics 33:1. 25-45.

Ruiz De Bravo Ahuja, Gloria. 1980. Mixe Tlahuitoltepec, Oaxaca. Archivo de Lenguas Indígenas de México.

Schoenhals, Alvin And Louise C. 1982. Vocabulario Mixe de Totontepec. Summer Institute of Linguistics. Hidalgo, Mexico.

Silvermann, Daniel. 1997. Laryngeal complexity in Otomanguean vowels. Phonology 14. 235-261.

Silvermann, Daniel, B. Blankenship, P. Kirk, and P. Ladefoged. 1995. Phonetic structures of Jalapa Mazatec. Anthropological Linguistics 37:1. 70-88.

Suslak, Dan. 2003. The Story of ö: Orthography and Cultural Politics in the Mixe Highlands. Pragmatics 13:4. 551-563.

Thomas, Kimberly D. and Alan Shaterian. 1990. Vowel length and Pitch in Yavapai. Papers from the 1990 Hokan-Penutian Languages Workshop. 144-53. Margaret Langdon ed. Carbondale, IL.

Torres Cisneros, Gustavo. 1997. Mixes. Comisión Nacional para el Desarrollo de los Pueblos Indígenas. http://www.cdi.gob.mx.

Van Haitsma, Julia Dieterman and Willard Van Haitsma. 1976. A Hierarchical Sketch of Mixe as spoken in San José El Paraiso. Summer Institute of Linguistics 44. Mexico.

Carmen Jany

University of California, Santa Barbara

Department of Linguistics

South Hall 3607

Santa Barbara, CA 93106-3100

cjany@umail.ucsb.edu 